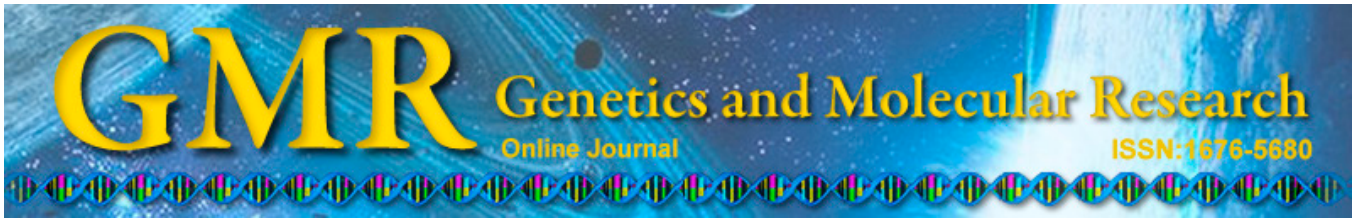

\title{
Mating system patterns of natural populations of Pinus koraiensis along its post-glacial colonization route in northeastern China
}

\author{
X. Sui ${ }^{1,2}$, F.J. Feng ${ }^{1}$, D. Zhao ${ }^{1}$, M. Xing ${ }^{1}$, X.Y. Sun ${ }^{1}$, S.J. Han ${ }^{4}$ and M.H. Li ${ }^{3,4}$ \\ ${ }^{1}$ Northeast Forestry University, Harbin, China \\ ${ }^{2}$ Institute of Natural Resources, Heilongjiang Academy of Sciences, \\ Harbin, China \\ ${ }^{3}$ Swiss Federal Research Institute WSL, Birmensdorf, Switzerland \\ ${ }^{4}$ State Key Laboratory of Forest and Soil Ecology, Institute of Applied Ecology, \\ Chinese Academy of Sciences, Shenyang, China \\ Corresponding author: F.J. Feng \\ E-mail: ffj9018@sina.com
}

Genet. Mol. Res. 14 (2): 4113-4124 (2015)

Received January 10, 2014

Accepted May 30, 2014

Published April 27, 2015

DOI http://dx.doi.org/10.4238/2015.April.27.26

\begin{abstract}
To understand the genetic mechanisms underlying the endangerment of Pinus koraiensis, we studied the mating system of 49 families of this species in 3 natural populations along its postglacial colonization route across $\sim 1500 \mathrm{~km}$ in northeastern China using the chloroplast simple sequence repeat technique. We analyzed 11 polymorphic loci with clear and repeating bands, and we calculated the multi-locus outcrossing rate $\left(\mathrm{t}_{\mathrm{m}}\right)$, single-locus outcrossing rate, inbreeding index, and fixation index $(F)$. Intra-population variation was not observed, but a large inter-population variation was observed in the outcrossing rate, and the $\mathrm{t}_{\mathrm{m}}$ increased from 0.767 (the south population) to 0.962 (the north population) along the post-glacial colonization route. The $t_{\mathrm{m}}$ values within a population did not change with time over 2 consecutive years. The $\mathrm{F}$ values for the 3 populations were $<0$, which
\end{abstract}


indicates an excess of heterozygotes. The mean effective number of alleles, Shannon diversity index, and Nei's genetic diversity index did not show a south-north pattern. The north population had the highest outcrossing rate but the lowest genetic diversity. The average genetic differentiation of $P$. koraiensis populations was 0.1251 , which was within the average range of woody plants with outcrossing and wind pollination. This study suggests that the current endangerment of $P$. koraiensis is not related to its genetic structure; perhaps it is mainly caused by man-made and natural disturbances such as deforestation and fire. Therefore, reducing disturbances and enhancing habitats, rather than the genetic aspects, play more important roles in the long-term protection of $P$. koraiensis.

Key words: Inbreeding depression; Outbreeding depression; Genetic diversity; Chloroplast simple sequence repeat; Endangered species

\section{INTRODUCTION}

The utilized plant mating system is a key biological factor affecting the genetic structure of a plant population (Ge, 1998). Mating systems of plant species present various evolutionary responses to natural selection, and the characteristics of mating systems affect the evolutionary rate of a species (Shaw et al., 1998). Studies on population-level mating systems promote a better understanding of population ecology, plant life history, and evolutionary biology. Plant mating systems can be studied by calculating the outcrossing and self-crossing rates of a population and their relative proportions of the generated offspring. Inbreeding depression is believed to be the main selection pressure in the evolution of a mating system, and the mating system determines whether inbreeding depression occurs ( $\mathrm{He}$ and $\mathrm{Ge}, 2001)$.

Chloroplast simple sequence repeat (cpSSR) is a new high-efficiency molecular marker technique with the advantages of microsatellite markers and characteristics of chloroplast DNA. The cpSSR has important implications for the identification of closely related species and the description of genetic differences at the individual and population levels. Recently, this technique has been widely used in the genetic analysis of plant populations, phylogeny, and inter-population gene flow (Kaundun and Matsumoto, 2002). Many studies used this method to study genetic differentiation, pollen transmission, gene flow, and evolution history in Pinus species such as P. resinos (Walter and Epperson, 2001), P. albicaulis (Richardson et al., 2002), P. pinaster (Liu and Yang, 2007), P. massoniana (Liu and Yang, 2007), P. yunnanensis (Liu and Yang, 2007), and P. taiwanensis (Liu and Yang, 2007) because of the characteristics of the paternal heredity of the chloroplast genome of Pinus species. For P. koraiensis Sieb. et Zucc., the application of this method focused on the population genetic diversity (Shao et al., 2007), and the gene flow and mating system were not involved.

P. koraiensis, a protected tree species in China with important economic and ecological values, is a dominant species in the climax vegetation, mixed needle broad-leaved forests in the eastern mountainous region of northeastern China. Forest use and habitat fragmentation have led to rapid decline in the distribution areas of natural $P$. koraiensis populations. For example, the natural distribution of $P$. koraiensis in China decreased from 630,000 ha in 1984 
to 180,000 ha in 2004 (State Forestry Administration of China, unpublished data). In addition to disturbance, we also need to understand the inbreeding and outcrossing depressions (Ge, 2000) to develop protection strategies for the endangered species. In this article, we studied the mating system of natural P. koraiensis populations using the cpSSR technique. We calculated the outcrossing and self-crossing rates of populations to infer whether inbreeding or outcrossing depressions exist in natural $P$. koraiensis populations. We aimed to explore the spatial and temporal patterns of the mating systems at the inter- and intra-population levels and their effects on the population genetic structure and offspring fitness to understand the mating mechanisms underlying the evolution process and reasons for that species being endangered.

\section{MATERIAL AND METHODS}

\section{Sites and plant materials}

P. koraiensis is a tertiary relict tree species that expanded its distribution along a postglacial colonization route from the refuge center in the Korean Peninsula northwards to Changbai Mountains, Lesser Khingan Mountains, and the Russian Far East. We selected natural P. koraiensis populations from south to north along the post-glacial expansion route in Baishilizi National Nature Reserve (south population, Kuandian, Liangning Province), Hongwei Forest Center (intermediate population, Lushuihe, Jilin Province), and Fenglin National Nature Reserve (north population, Yichun, Heilongjiang Province) in northeastern China (Figure 1 and Table 1).

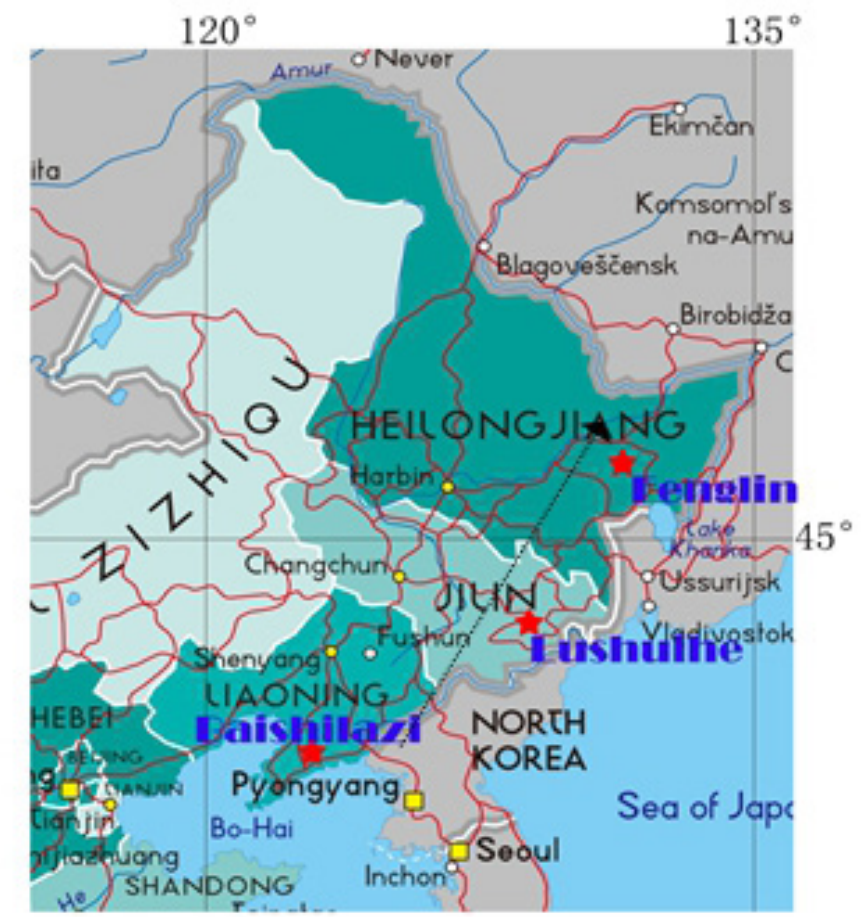

Figure 1. Geographic locations of the natural Pinus koraiensis populations studied along the post-glacial colonization route in northeastern China. 
X. Sui et al.

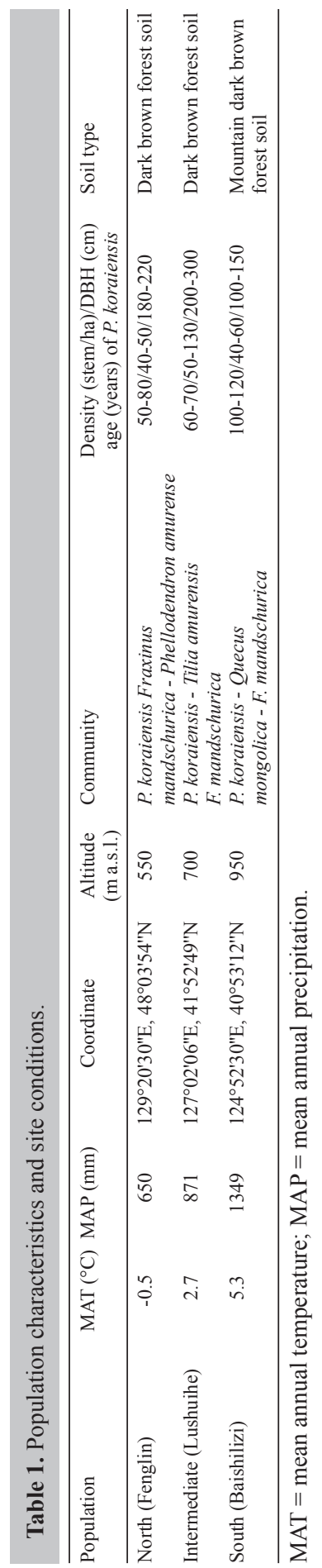


To understand the inter-population variation, we selected 18 maternal individuals from the north (Fenglin) and south populations (Baishilizi) and 13 individuals from the intermediate population (Lushuihe) in September 2010 (Figure 1 and Table 1). The distance between any 2 individuals within a population was $>300 \mathrm{~m}$. Ten seeds were randomly selected from $>20$ cones collected from each maternal tree. A total of 490 offspring (seed embryos) were obtained. DNA was extracted from the seed embryos for further analysis. To study the time-dependent variation, we took samples from the 18 individuals in the north population in September 2011 (i.e., 2010 vs 2011).

\section{DNA extraction}

The seed embryo DNA was extracted using the traditional cetyltrimethylammonium bromide method (Clark et al., 1998). The DNA concentration and purity were examined by $0.8 \%$ agarose gel electrophoresis and ultraviolet spectrophotometer.

\section{cpSSR-polymerase chain reaction (PCR) system}

The amplification program was set according to Feng et al. (2010). PCR was carried out in a $20-\mu \mathrm{L}$ volume containing $1 \mathrm{X}$ buffer, 50-120 ng template DNA, $2.0 \mathrm{mM}$ $\mathrm{Mg}^{2+}, 0.2 \mathrm{mM}$ of each dNTP, $0.5 \mu \mathrm{M}$ reverse primer, $0.5 \mu \mathrm{M}$ forward primer, and $0.4 \mathrm{U}$ Taq polymerase.

An initial denaturation at $94^{\circ} \mathrm{C}$ for $5 \mathrm{~min}$ was followed by 35 cycles of $60 \mathrm{~s}$ at $94^{\circ} \mathrm{C}$, $60 \mathrm{~s}$ at $35^{\circ} \mathrm{C}$, and $2 \mathrm{~min}$ at $72^{\circ} \mathrm{C}$ and a final extension of $7 \mathrm{~min}$ at $72^{\circ} \mathrm{C}$. Sequence data were obtained on a Gene Amp PCR System (ABI Cor., USA). dNTPs and Taq enzymes were provided by TaKaRa Biotechnology Co., Ltd. (Dalian, China).

\section{Selection of primers}

The cpSSR primers used in this study were obtained from published results for Pinus species such as $P$. densiflora, $P$. pinaster, $P$. sylvestris, and P. contorta (Provan et al., 1998; Marshall et al., 2002; Ribeiro et al., 2002; Dzialuk et al., 2009). A total of 70 pairs of cpSSR primers were synthesized for the first selection, and 47 pairs with significant main bands were selected. Finally, 9 pairs of cpSSR primers with high polymorphism were used (Table 2).

\section{Table 2. cpSSR primer sequences.}

\begin{tabular}{|c|c|c|}
\hline Primers & Forward primer sequence $\left(5^{\prime}-3^{\prime}\right)$ & Reverse primer sequence $\left(5^{\prime}-3^{\prime}\right)$ \\
\hline ccSSR-3 & CCAAAAGCTGACATAGATGTTA & TTTCATTCGGCTCCTTTATG \\
\hline ccSSR-14 & GGGTATAATGGTAGATGCCC & GCCGTAGTAAATAGGAGAGAAA \\
\hline $\operatorname{ccSSR}-15$ & GCTTATGACCTCCCССТCTATGC & TGCATTACAGACGTATGATCATTA \\
\hline Pt79951 & CTTTTGTTTTTCAACAATTGCA & ACATCTATCTCCCATATCGGC \\
\hline РCP1289 & TCCTGGTTCCAGAAATGGAG & TAATTTGGTTCCAGAATTGCG \\
\hline РCP45071 & ACTGGTCTGATCGACCCAAT & TTCTACACTTGCGGAAACCC \\
\hline PCP79987 & TTTTCAACAATTGCATTTACCG & GGCGGGATAGGAGTCTTTTC \\
\hline 10F/RR & CAGAAGCCCAAGCTTATGGC & CGGATTGATCCTAACCATAC \\
\hline $69 \mathrm{~F} / \mathrm{R}$ & TTTCGGGCTCCACTGTTATC & CGTACTCAATTTGTTACTAC \\
\hline
\end{tabular}




\section{Product examination}

Amplified fragments were segregated on $6 \%$ denatured polyacrylamide gels with 7 $\mathrm{M}$ urea and 0.5X Tris-boric acid-ethylenediaminetetraacetic acid electrophoretic buffer. After electrophoresis, the gel was stained with silver nitrate solution. The bands were scanned using a Founder scanner U 430.

\section{Data analysis}

The MLDT program was used to evaluate the multi-locus $\left(t_{m}\right)$ and single-locus $\left(t_{s}\right)$ outcrossing rates, standard deviations, inbreeding index $\left(\mathrm{t}_{\mathrm{m}}-\mathrm{t}_{\mathrm{s}}\right)$, and fixation index $(\mathrm{F})$ according to the mixed mating model (Ritland, 1990). The POPGENE 32 software (Yeh et al., 1999) was used to calculate Nei's gene diversity index, observed number of alleles, Shannon's diversity index, effective number of alleles, and genetic differentiation.

\section{RESULTS}

\section{Differences in inter-population mating systems}

Nine cpSSR primers (Table 2) were used for the amplification of 490 offspring samples from 49 individual families of 3 populations. A total of 11 polymorphic loci with clear and repeating bands were obtained, and their fragment lengths ranged from 130 to $500 \mathrm{bp}$ (Figure 2).

Analysis of the 11 polymorphic loci (Figure 2) revealed that both the $t_{\mathrm{m}}$ and $\mathrm{t}_{\mathrm{s}}$ values had a consistent changing pattern (Table 3 ) that followed the following decreasing order: the north population $>$ the intermediate population $>$ the south population. For example, the $t_{m}$ values decreased from 0.962 (north population) to 0.767 (south population) (Table 3). The 3 populations had a low inbreeding level and an F value of less than zero (Table 3), indicating the existence of excess heterozygotes. Based on the $\mathrm{F}$ values calculated for the 3 populations (Table 3), the south population had the mating pattern that was closest to random mating.

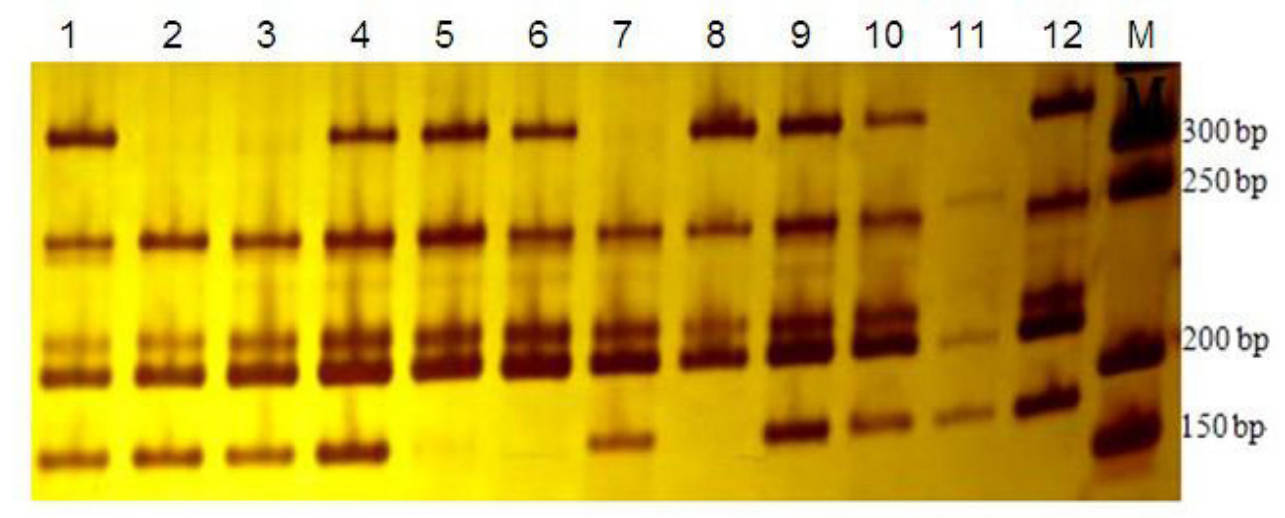

Figure 2. Amplification of the partial samples from the south population (Baishilizi, Figure 1, Table 1) by the primer 69F/R. Lane $M$ : marker. 
Table 3. Comparison of mating systems between the three Pinus koraiensis populations (mean values $\pm \mathrm{SD}$, $\mathrm{N}=18$ for the north and the south population, and $\mathrm{N}=13$ for the intermediate population).

\begin{tabular}{|c|c|c|c|c|}
\hline Population & Multi-locus outcrossing rate $\left(\mathrm{t}_{\mathrm{m}}\right)$ & Single-locus outcrossing rate $\left(\mathrm{t}_{\mathrm{s}}\right)$ & Inbreeding index $\left(\mathrm{t}_{\mathrm{m}}-\mathrm{t}_{\mathrm{s}}\right)$ & Fixed index $(\mathrm{F})$ \\
\hline North (Fenglin) & $0.962 \pm 0.000$ & $1.116 \pm 0.160$ & $-0.154 \pm 0.010$ & -0.300 \\
\hline Intermediate (Lushuihe) & $0.804 \pm 0.023$ & $0.778 \pm 0.011$ & $0.026 \pm 0.000$ & -0.300 \\
\hline South (Baishilizi) & $0.767 \pm 0.060$ & $0.771 \pm 0.035$ & $-0.004 \pm 0.031$ & -0.077 \\
\hline
\end{tabular}

\section{Mating system distribution in different individuals}

Statistical significance analysis showed that there was no significant difference in the $t_{m}$ and $t_{s}$ values among individuals within a population (Table 4). The $t_{m}$ and $t_{s}$ values of the 13 individuals in the intermediate population (Lushuihe) ranged from 0.5 to 1.0 (accounting for $31 \%$ of the total outcrossing rates for the 13 individuals) and from 1.0 to 1.5 ( $38 \%$ of the total rates), respectively. The $\mathrm{t}_{\mathrm{m}}$ and $\mathrm{t}_{\mathrm{s}}$ values of the 18 individuals in the north (Fenglin) population were in the range of 0.5 to 1.0 (39\% of the total rates) and 1.0 to 1.5 (33\%), respectively. The $t_{\mathrm{m}}$ of the south (Baishilizi) population was in the range of both 0.5 to 1.0 and 1.0 to 1.5 , each accounting for $39 \%$ of the total rate for the 18 individuals, whereas the $t_{s}$ values were in the range of 1.0 to 1.5 , accounting for $50 \%$ of that of the 18 individuals. The $\mathrm{t}_{\mathrm{m}}$ and $\mathrm{t}_{\mathrm{s}}$ values had a similar normal distribution for each of the 3 populations (Figures 3 and 4).

Table 4. Statistical significance analysis of multi-locus (tm) and single-locus (ts) outcrossing rates among individuals within a population.

\begin{tabular}{lccc}
\hline Outcrossing rate & North (Fenglin) & Intermediate (Lushuihe) & South (Baishilizi) \\
\hline $\mathrm{t}_{\mathrm{m}}$ & $0.78^{\text {ns }}$ & $1.05^{\text {ns }}$ & $0.97^{\text {ns }}$ \\
$\mathrm{t}_{\mathrm{s}}$ & $1.07^{\text {ns }}$ & $1.17^{\text {ns }}$ & $0.98^{\text {ns }}$ \\
\hline
\end{tabular}

'ns' means non-significant difference $(\mathrm{P}>0.05)$ in $\mathrm{t}_{\mathrm{m}}$ or $\mathrm{t}_{\mathrm{s}}$ among individuals within a population.

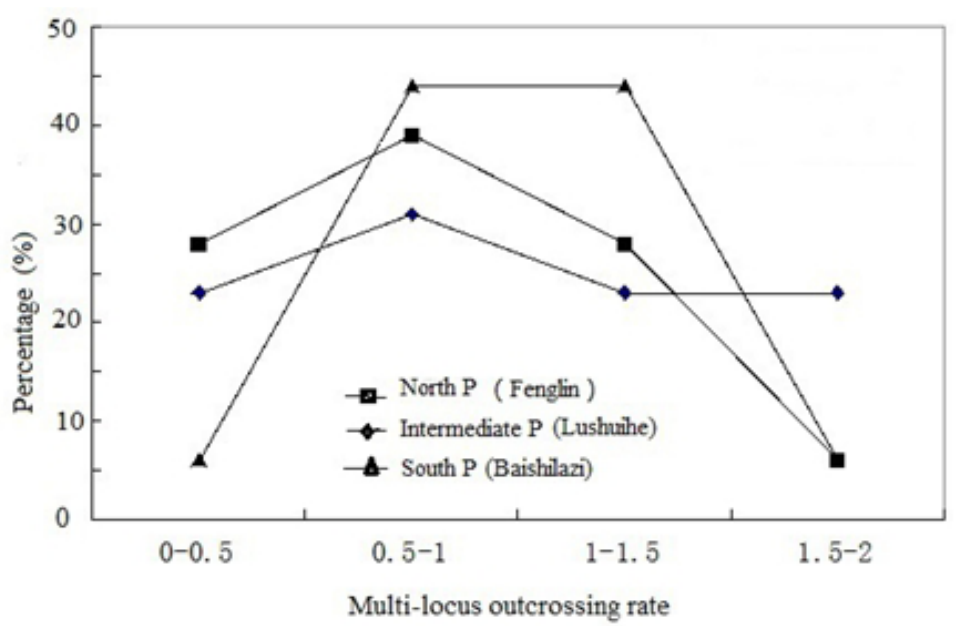

Figure 3. Distribution of the multi-locus outcrossing rate in different individuals of Pinus koraiensis populations (P). 


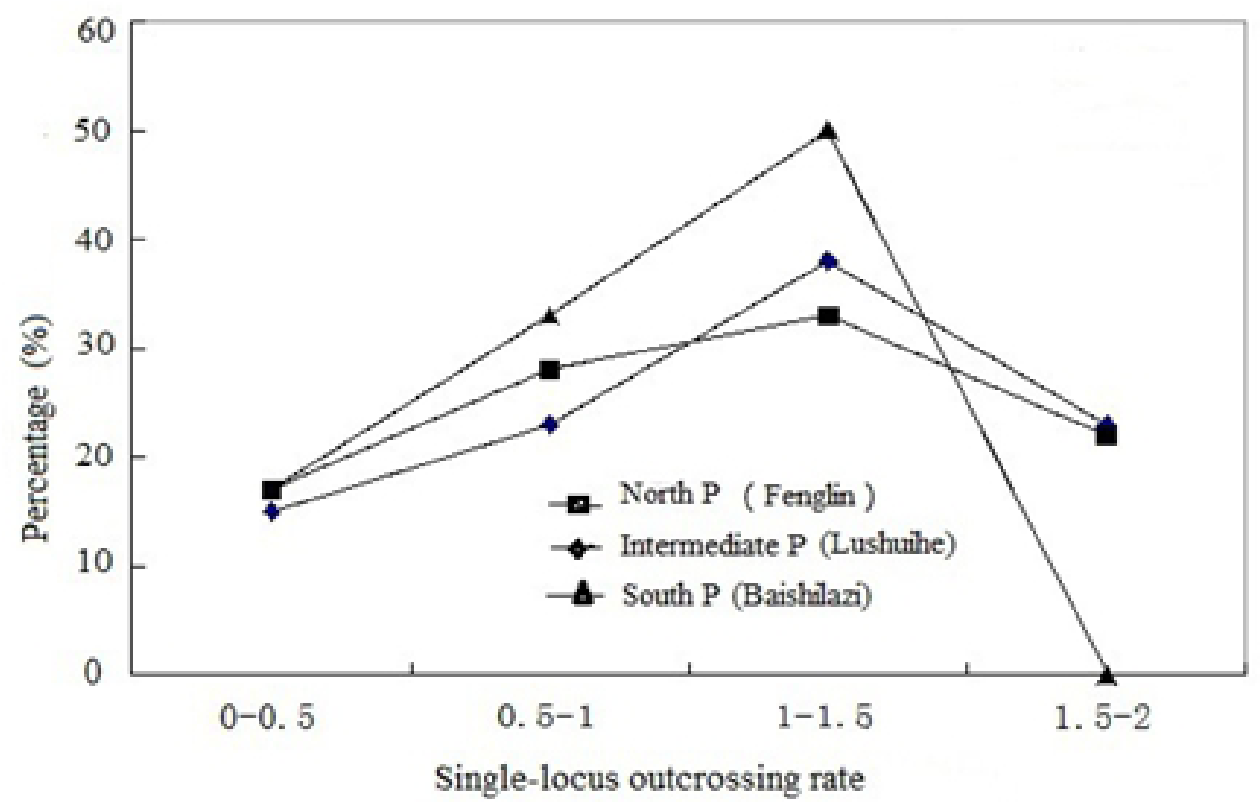

Figure. 4. Distribution of the single-locus outcrossing rate in different individuals of Pinus koraiensis populations (P).

\section{Dynamics of mating systems}

The $t_{\mathrm{m}}$ and $\mathrm{t}_{\mathrm{s}}$ values for the north (Fenglin) population were 0.966 and 0.993 in 2011 and 0.962 and 1.116 in 2010 , respectively, showing a non-significant difference in the $\mathrm{t}_{\mathrm{m}}$ values but a significant difference in the $t_{\mathrm{s}}$ values between the 2 consecutive years.

\section{Genetic diversity and differentiation}

The 3 populations had the same patterns of effective number of alleles, Shannon diversity index, and Nei's diversity index: they followed the decreasing order of intermediate population (Lushuihe) $>$ south population (Baishilizi) $>$ north population (Fenglin) (Table 5). The north population had the highest outcrossing rate but the lowest genetic diversity (Table 5).

The mean total genetic diversity $\left(H_{\mathrm{T}}\right)$ of $P$. koraiensis populations was 0.1260 . The intra-population genetic diversity $\left(H_{\mathrm{S}}\right)$ was 0.1102 , and the inter-population genetic diversity $\left(D_{\mathrm{ST}}\right)$ was 0.0158 . The average genetic differentiation was 0.1251 . The $H_{\mathrm{S}}$ and $D_{\mathrm{ST}}$ accounted for 87.5 and $12.5 \%$ of $H_{\mathrm{T}}$, respectively.

Table 5. Genetic diversity of the three Pinus koraiensis populations.

\begin{tabular}{lccccc}
\hline Populations & $\begin{array}{c}\text { Numbers } \\
\text { of samples }\end{array}$ & $\begin{array}{c}\text { Averaged numbers } \\
\text { of alleles }\end{array}$ & $\begin{array}{c}\text { Averaged effective } \\
\text { numbers of alleles }\end{array}$ & $\begin{array}{c}\text { Shannon diversity } \\
\text { index }\end{array}$ & $\begin{array}{c}\text { Nei diversity } \\
\text { index }\end{array}$ \\
\hline North (Fenglin) & 180 & $1.5000^{\mathrm{a}}$ & $1.1058^{\mathrm{a}}$ & $0.1481^{\mathrm{a}}$ & $0.0835^{\mathrm{a}}$ \\
Intermediate (Lushuihe) & 130 & $1.5000^{\mathrm{a}}$ & $1.3009^{\mathrm{b}}$ & $0.2568^{\mathrm{a}}$ & $0.1727^{\mathrm{a}}$ \\
South (Baishilizi) & 180 & $1.4444^{\mathrm{a}}$ & $1.1887^{\mathrm{ab}}$ & $0.1963^{\mathrm{a}}$ & $0.1241^{\mathrm{a}}$ \\
\hline
\end{tabular}

Mean values are given. Different letters in the same column indicate significant difference at $\mathrm{P}<0.05$ level. 


\section{DISCUSSION}

\section{Inbreeding and outcrossing depression}

This study found that the outcrossing rate of $P$. koraiensis populations ranged from 0.767 to 0.962 (Table 3), which is at the medium level of data published for Pinus species. The outcrossing rate was $0.451-0.522$ for P. bungeana ( $\mathrm{Li}$ and $\mathrm{Gu}, 2004), 0.864$ for natural P. tabuliformis populations (Zhang et al., 2000), 0.950 for P. sylvestris (Korshikov and Demkovich, 2010), 1.098 for P. massoniana (Tan et al., 2012), and 1.020 and 1.000 for $P$. strobus and P. contorta, respectively (Beaulieu and Simon, 1995).

The genetic basis of inbreeding depression is considered as heterozygote vigor and homozygosis of deleterious recessive genes (Charlesworth and Charlesworth, 1999). According to Wright (1969), $-1<\mathrm{F}<0$ indicates an excess of heterozygotes and a deficiency of homozygotes. The Wright $F$ values obtained in this study ( -0.300 to -0.077 ; Table 3$)$ showed that an excess of heterozygotes and a deficiency of homozygotes existed in all 3 of the populations, indicating that the homozygosis of deleterious recessive gene occurs with a low probability; therefore, there is a low probability of inbreeding depression.

Genetic differentiation has been used to judge whether outcrossing depression occurs. Offspring fitness will decline when genotype differences of parents exceed a certain threshold (Ge, 2000). Similarly, Becher et al. (2006) stated that outcrossing depression occurs only when the genetic differentiation exceeds a certain threshold. This study found that the average genetic differentiation value was 0.1251 , accounting for $12.5 \%$ of the total genetic diversity. This result is in agreement with our previous results $\left(G_{\mathrm{ST}}=0.1468\right.$; Feng et al., 2009). Hamrick et al. (1992) reported that the inter-population gene variation for most wind-pollinated and cross-pollinated woody plants accounts for $10 \%$ of the total gene variation. The genetic differentiation of the $P$. koraiensis populations is at a medium level, suggesting that outcrossing depression may not be possible in this species.

Stebbins et al. (1957) concluded that the mating system more strongly influences the plant genetic structure than any other life-cycle factor. There is a common view that the mating system affects population genetic diversity mainly by influencing heterozygosity and the coefficient of genetic differentiation $(\mathrm{Ge}, 1998)$. In this study, we found that the inter-population genetic variation was $12.5 \%$, which was similar to that reported by Hamrick et al. (1990), who found that the inter-population variation accounted for $51 \%$ of the total genetic variation of self-mating species, whereas it only accounted for $12 \%$ of the genetic variation of outcrossing species. Our results suggest that $P$. koraiensis has an outcrossingdominated mixed mating type.

\section{Stability of the mating system}

Previous studies have found that the mating system of plant species is dynamic. For example, the outcrossing rate may have large variations among populations of the same species, among different individuals within a population, or in the same individual in consecutive years (Hamrick, 1990). The mating system is influenced not only by genetic factors but also by various environmental factors such as altitude, temperature, humidity, population size, and density (Neale and Adams, 1985). Carneiro et al. (2011) also found that the felling period has impacts on the mating system and pollen transmission of Hymenaea courbaril populations. 
Hence, the relatively large inter-population variation in the outcrossing rate ( 0.767 for the south population to 0.962 for the north population) that was observed in this study (Table 3) may be a result of environmental variations among the 3 populations across a large scale of $1500 \mathrm{~km}$ (Figure 1 and Table 1). Moreover, the outcrossing rates of the populations showed an increasing trend along the evolutionary expansion route from south to north; this implies that natural selection pressure constantly enhances the outcrossing level in the evolution process of $P$. koraiensis. Shaw et al. (1998) stated that the evolution and changes in the population mating system are profoundly influenced by new selective pressures. Generally, inbreeding can improve the probability of homozygosis of recessive gene, which may lead to a loss of detrimental genes in a population, although these lost genes might be able to adapt to a changing environment under global environmental change (Charlesworth and Charlesworth, 1995). Therefore, an inbreeding population has a short lifetime compared to an outcrossing population (Holsinger, 2000). P. koraiensis is a typical species with long longevity; it tends to select the strategy to improve the outcrossing rate in its evolution.

We did not observe significant differences in the outcrossing rate among individuals within a population, which showed a normal distribution (Figures 3 and 4). This result may be attributed to the consistent ecological and evolutionary consequences within a population, leading to a stable mating system with small intra-population variation. Similarly, Wang et al. (2012) found that the $t_{\mathrm{m}}$ values of 15 Tsoongiodendron odorum individuals ranged from 0.885 to 0.999 , with a non-significant difference. Tan et al. (2012) also found a non-significant difference in the $\mathrm{t}_{\mathrm{m}}$ values (ranging from 1.033 to 1.200) of 8 individuals obtained from a seed orchard of P. massoniana. However, De-Lucas et al. (2008) showed that there was a significant difference in the $\mathrm{t}_{\mathrm{m}}$ values among $P$. pinaster individuals growing across areas in the Mediterranean region, which may be co-determined by abiotic factors across areas and biotic factors such as florescence synchronism, tree height, and canopy size among individuals in different populations (Tamaki et al., 2009).

The north (Fenglin) population showed a similar $\mathrm{t}_{\mathrm{m}}$ value in $2010(0.966)$ as it did in 2011 (0.962). It seemed that there is non-significant variation in the mating system of $P$. koraiensis across a short time series. This result agrees with the findings by Zhang et al. (2009), who also found similar values of outcrossing rates (1.200 and 1.072) in P. massoniana seeds collected in 2 consecutive years. Burczyk (1998) showed that the outcrossing rates of $P$. sylvestris in a clonal seed orchard were $0.976,0.966$, and 0.962 in 3 consecutive years. Zhang et al. (2004) investigated the outcrossing rates of $P$. tabulaeformis in a clonal seed orchard before and after thinning conducted in 1994, and they found that the outcrossing rate was 0.975 in 1984 and 0.962 in 1993 (before thinning), and 0.795 in 1996 and 0.801 in 2000 (after thinning). Our results indicate that $P$. koraiensis, like other Pinus species, has a non-significant variation in the outcrossing rate in a short time sequence. Unfortunately, long-term variations in the outcrossing rate of Pinus species are unavailable. Thus, investigations of long-term variations in the outcrossing rate of $P$. koraiensis trees are needed to reach a more accurate conclusion. Our results did not show differences in the $t_{\mathrm{m}}$ values, but there was a significant difference in the $t_{s}$ values across 2 consecutive years, which suggests the use of $t_{s}$ values to study the time-dependent mating system of a population. Similarly, Brown et al. (1985) found that the outcrossing rate had a small impact on polymorphic locus estimates but a large impact on single locus estimates.

$\mathrm{Li}$ and $\mathrm{Gu}$ (2004) found that the endangerment of $P$. bungeana was mainly caused by a high inbreeding rate in the mating system, while the endangered status of $P$. ponderos and 
Cathaya argyrophylla was attributed to a low genetic diversity (Allendorf et al., 1982; Mosseler et al., 1992). This study found that the current endangerment of $P$. koraiensis did not seem to be related to its genetic structure; perhaps, the endangerment was mainly caused by man-made and natural disturbances such as deforestation and fire disaster. Therefore, reducing disturbance and enhancing habitats, rather than genetic aspects, play more important roles in the long-term protection of $P$. koraiensis. Moreover, the genetic variation of $P$. koraiensis exists among individuals within a population (Table 5), which suggests that it is also needed to protect and preserve the diversity within a population. For instance, collecting seeds from many different possible individuals within a population may help to maintain that genetic diversity in species to keep pace with global changes in the future (Wang, 1998).

\section{ACKNOWLEDGMENTS}

Research supported by the Fundamental Research Funds for the Central Universities (\#DL10CA05), the National Natural Sciences Foundation of China (Grant \#41105104), and the National Natural Science Foundation of China (Grant \#41330530).

\section{REFERENCES}

Allendorf FW, Knudsen KL and Blake GM (1982). Frequencies of null alleles at enzyme loci in natural populations of ponderosa and red pine. Genetics 100: 497-504.

Beaulieu J and Simon JP (1995). Mating system in natural populations of eastern white pine in Quebec. Can. J. Forest Res. 25: 1697-1703.

Becker U, Reinhold T and Matthies D (2006). Effects of pollination distance on reproduction and offspring performance in Hypochoeris radicata: Experiments with plants from three European regions. Biol. Conserv. 132: 109-118.

Brown A, Barrett S and Moran G (1985). Mating system estimation in forest trees: models, methods and meanings. In: Population genetics in forestry (Gregorius HR, ed.). Springer, Berlin, 32-49.

Burczyk J (1998). Mating system variation in a Scots pine clonal seed orchard. Silvae Genet. 47: 155-157.

Carneiro F, Lacerda A, Lemes M, Gribel R, et al. (2011). Effects of selective logging on the mating system and pollen dispersal of Hymenaea courbaril L. (Leguminosae) in the Eastern Brazilian Amazon as revealed by microsatellite analysis. Forest Ecol. Manag. 262: 1758-1765.

Charlesworth B and Charlesworth D (1995). Quantitative genetics in plants: the effect of the breeding system on genetic variability. Evolution 49: 911-920.

Charlesworth B and Charlesworth D (1999). The genetic basis of inbreeding depression. Genet. Res. 74: 329-340.

Clark, Gu HY and Qu LJ (1998). Plant molecular biology laboratory manual. Higher Education Press, Beijing, 131.

De-Lucas A, Robledo-Arnuncio J, Hidalgo E and González-Martínez S (2008). Mating system and pollen gene flow in Mediterranean maritime pine. Heredity 100: 390-399.

Dzialuk A, Muchewicz E, Boratyński A, Montserrat J, et al. (2009). Genetic variation of Pinus uncinata (Pinaceae) in the Pyrenees determined with cpSSR markers. Plant Syst. Evol. 277: 197-205

Feng FJ, Chen MM, Zhang DD, Sui X, et al. (2009). Application of SRAP in the genetic diversity of Pinus koraiensis of different provenances. Afr. J. Biotechnol. 8: 1000-1008.

Feng FJ, Zhao D, Sun XY, Han SJ, et al. (2010). Establishment and optimization of the SSR-PCR reaction system in Pinus koraiensis Sieb. et Zucc. Nonwood Forest. Res. 28: 35-40.

Ge S (1998). Retrospect and prospect of plant population genetic structure. In: Advances in plant science. 1st edn. Higher Education Press, Beijing, 1-15.

Ge S (2000). Speciation in plants and its research progress. In: Advances in plant science. 4th edn. Higher Education Press, Beijing, 3-15.

Hamrick J (1990). Isozymes and the analysis of genetic structure in plant populations. In: Isozymes in plant biology. Springer, Netherlands, 66-70.

Hamrick JL, Godt MJW, Brown AHD, Clegg MT, et al. (1990). Allozyme diversity in plant species. Plant Pop. Genet. Breed. Genet. Res. 43-63. 
Hamrick JL, Godt MJW and Sherman-Broyles SL (1992). Factors influencing levels of genetic diversity in woody plant species. New Forests 6: 95-124.

$\mathrm{He} \mathrm{TH}$ and Ge S (2001). Mating system, paternity analysis and gene flow in plant populations. Acta Phytoecol. Sin. 25: 144-154.

Holsinger KE (2000). Reproductive systems and evolution in vascular plants. Proc. Natl. Acad. Sci. U. S. A. 97: $7037-$ 7042.

Kaundun SS and Matsumoto S (2002). Heterologous nuclear and chloroplast microsatellite amplification and variation in tea, Camellia sinensis. Genome 45: 1041-1048.

Korshikov II and Demkovich AE (2010). Genetic polymorphism of plus-tree clones and their seed progeny in the Scotch pine clone plantation. Cytol. Genet. 44: 28-36.

Li B and Gu WC (2004). Mating system and genetic diversity proportion in Pinus bungeana. Forest Res. 17: 19-25.

Liu ZL and Yang X (2007). Genetic diversity and differentiation of five pines using cpSSR and AFLP markers. Acta Bot. Boreal 27: 2385-2392.

Marshall HD, Newton C and Ritland K (2002). Chloroplast phylogeography and evolution of highly polymorphic microsatellites in lodgepole pine (Pinus contorta). Theor. Appl. Genet. 104: 367-378.

Mosseler A, Egger KN and Hughes GA (1992). Low levels of genetic diversity in red pine confirmed by random amplified polymorphic DNA markers. Can. J. For. Res. 22: 1332-1337.

Neale D and Adams W (1985). Allozyme and mating-system variation in balsam fir (Abies balsamea) across a continuous elevational transect. Can. J. Bot. 63: 2448-2453.

Provan J, Soranzo N, Wilson N, McNicol J, et al. (1998). Gene-pool variation in Caledonian and European Scots pine (Pinus sylvestris L.) revealed by chloroplast simple-sequence repeats. Proc. Biol. Sci. 265: 1697-1705.

Ribeiro MM, Mariette S, Vendramin GG, Szmidt AE, et al. (2002). Comparison of genetic diversity estimates within and among populations of maritime pine using chloroplast simple-sequence repeat and amplified fragment length polymorphism data. Mol. Ecol. 11: 869-877.

Richardson BA, Brunsfeld SJ and Klopfenstein NB (2002). DNA from bird-dispersed seed and wind-disseminated pollen provides insights into postglacial colonization and population genetic structure of whitebark pine (Pinus albicaulis). Mol. Ecol. 11: 215-227.

Ritland K (1990). A series of FORTRAN computer programs for estimating plant mating systems. J. Hered. 81: 235-237.

Shao D, Pei Y and Zhang HQ (2007). cpSSR analysis of variation of genetic diversity in temporal dimension of natural population of Pinus koraiensis in Liangshui National Nature Reserve. Bull. Bot. Res. 27: 473-477.

Shaw RG, Byers DL and Shaw FH (1998). Genetic components of variation in Nemophila menziesii undergoing inbreeding: morphology and flowering time. Genetics 150: 1649-1661.

Stebbins GL (1957). Self-fertilization and population variability in the higher plants. Am. Nat. 91: 337-354.

Tamaki I, Setsuko S and Tomaru N (2009). Estimation of outcrossing rates at hierarchical levels of fruits, individuals, populations and species in Magnolia stellata. Heredity 102: 381-388.

Tan XM, Zhou ZC, Jin GQ and Zhang Y (2012). Genetic diversity and mating system analysis of Pinus massoniana in a second-generation clonal seed orchard. Sci. Silv. Sin. 48: 69-74.

Walter R and Epperson BK (2001). Geographic pattern of genetic variation in Pinus resinosa: area of greatest diversity is not the origin of postglacial populations. Mol. Ecol. 10: 103-111.

Wang CY (1998). Plant mating system in relation to strategies for the conservation and breeding of endangered species. Biodiversity Sci. 6: 298-303.

Wang X, Wang J, Jiang JH and Kang M (2012). Genetic diversity and the mating system in a fragmented population of Tsoongiodendron odorum. Biodiversity Sci. 20: 676-684.

Wright S (1969). Evolution and Genetics of Population. Vol. 2. The Theory of Gene Frequencies. University of Chicago Press, Chicago.

Yeh F, Yang R-C and Boyle T (1999). PopGene Version 131: Microsoft Window-based freeware for population genetic analysis. University of Alberta and Centre for International Forestry Research, Calgary, 11-23.

Zhang DM, Li Y, Shen XH, Zhang CX, et al. (2000). A primary study on the mating system of three different populations within one improvement procedure of Pinus tabulaeformis Carr. J. Beijing Forestry Univ. 22: 13-18.

Zhang DM, Zhang HX, Shen XH and Li Y (2004). Study on temporal and spatial change of the mating system in a seed orchard of Pinus tadulaeformis. Sci. Silv. Sin. 40: 71-77.

Zhang W, Gong J and Ji KS (2009). Analyses on the mating system in seedling seed orchard of Pinus massoniana. Sci. Silv. Sin. 45: 22-26. 